\title{
Caracterización de materiales e intervención sobre un tramo de la muralla Sur de Jaén
}

\author{
Francisco Martín* \\ Beatriz Martín***
}

\section{INTRODUCCIÓN}

El presente estudio aborda las labores relacionadas con la restauración del tramo de muralla medieval de la c/Carrera de Jesús, localizado al sur de la ciudad de Jaén (Figura I). Este proyecto se llevó a cabo en el año 1998 por la Escuela-Taller de la capital jienense, en coordinación con los autores de este trabajo. La participación de la Escuela-Taller hizo posible la restauración del tramo que quedó pendiente en la intervención realizada por D. Luis Berges Roldán en 1973 (BERGES, 1986), sirviendo de soporte a la formación de los alumnos-trabajadores de la escuela y realizándose en todo momento bajo la supervisión y control de personal especializado en este tipo de intervenciones.

El tramo de muralla restaurado tiene una longitud total de 25 metros, encontrándose limitado en uno de sus extremos por un torreón cilíndrico de 3,50 metros de diámetro, anteriormente cubierto de forma parcial por el inmueble $n^{\circ} 4$ del Cantón de Jesús (demolido en esta intervención), y en el otro extremo por el inmueble $n^{\circ} 2$ de la citada calle. En esta zona, la muralla tiene una altura media de 9 metros y un espesor de 2,60 metros. El sistema constructivo básico se configuró en la etapa almohade y consistía en muros de tapial de gran espesor; en épocas posteriores se procedió a reforzar el muro original mediante revestimientos de mampostería, dando origen en otras ocasiones a un sistema nuevo consistente en el levantamiento de dos muros de mampostería paralelos, a modo de encofrado, que luego se rellenan de una mezcla de tierra y cal.

En una fase inicial, se procedió a la caracterización y examen de los materiales presentes, así como al estudio de las patologías y estado de conservación de los elementos a restaurar, con lo que se realizó la propuesta de intervención que finalmente se llevó a cabo. Cabe destacar la coordinación científica de los trabajos ejecutados, que contemplaron en todo momento los criterios de intervención adecuados y basados en los estudios previos sobre los materiales restaurados.

El objetivo de este trabajo es la presentación de los resultados obtenido en las labores de restauración del tramo de muralla considerado, con el fin de aportar una visión integrada de dicha intervención en los campos del estudio analítico de materiales y del proceso restaurador realizado.

\footnotetext{
* Geólogo del Departamento de Edafología de la Universidad de Granada.

*** Restauradora de la Empresa TARMA S.C.A.
} 


\section{CARACTERIZACIÓN DE MATERIALES}

\section{I. Metodología utilizada}

Los estudios previos al proyecto de restauración deben consistir en el conjunto de tareas capaces de aportar el más amplio conocimiento posible de la obra a intervenir, siendo la herramienta básica en la toma de decisiones posteriores.

El primer acercamiento al monumento se realizó mediante una observación detallada "in situ" de la obra, a través de la cual se profundizó en el conocimiento del monumento en aspectos como: técnica constructiva, materiales constitutivos, estado de deterioro, etc. Tras esta primera fase, se establecieron las principales patologías presentes y se procedió a la toma de muestras según los criterios básicos de minimización del impacto estético en las extracciones de material y de representatividad del muestreo, mediante la selección adecuada de las zonas y materiales a muestrear. Por un lado, se procedió a la caracterización del mortero de unión de mampostería y del relleno interior de la muralla; y por otro, se analizaron los principales procesos de degradación, estudiándose de forma detallada tanto las costras de alteración superficiales, como las eflorescencias salinas.

Las técnicas empleadas en estos estudios fueron de carácter destructivo, para lo cual el muestreo fue realizado de tres formas diferentes en función del tipo de análisis al que se sometió cada muestra. Se tomaron fragmentos de unos pocos centímetros cúbicos, para la realización de láminas delgadas y su posterior estudio al microscopio petrográfico, material disgregado para la elaboración de las granulometrías, y raspado superficial de las sales y costras de suciedad para la realización de difractogramas de rayos $X$.

Los materiales analizados en este tramo de muralla, junto con la técnica analítica empleada, y la denominación otorgada en los diferentes estudios realizados, se muestran en la Tabla I.
Tabla 1.

Muestras analizadas y técnicas analíticas empleadas

\begin{tabular}{|c|c|c|}
\hline MUESTRA & DESCRIPCION & TÉCNICAS ANALITICAS \\
\hline $\mathrm{MI}$ & $\begin{array}{l}\text { Mortero de unión de } \\
\text { mampostería (muro) }\end{array}$ & $\begin{array}{l}\text { Microscopía óptica } \\
\text { Granulometría }\end{array}$ \\
\hline$M 2$ & $\begin{array}{l}\text { Mortero de unión de } \\
\text { mampostería (torreón) }\end{array}$ & $\begin{array}{l}\text { Microscopía óptica } \\
\text { Granulometría }\end{array}$ \\
\hline $\mathrm{R}$ & $\begin{array}{l}\text { Material de relleno } \\
\text { interior de muro }\end{array}$ & Granulometría \\
\hline SALES & Eflorescencias salinas & Difracción de rayos $X$ \\
\hline SUC & $\begin{array}{l}\text { Costra de suciedad } \\
\text { superficial }\end{array}$ & Difracción de rayos $X$ \\
\hline SUC_VEG & $\begin{array}{c}\text { Costra de suciedad } \\
\text { asociada a vegetación }\end{array}$ & Difracción de rayos $X$ \\
\hline
\end{tabular}

Las técnicas analíticas empleadas fueron seleccionadas en función de su adecuación a la consecución de los objetivos de caracterización marcados, así como a la disponibilidad económica del proyecto. A continuación se describe brevemente la metodología utilizada en cada caso:

La Difracción de Rayos $X$ fue realizada en un Difractómetro Philips PW 17।0, equipado con rendija automática, del Departamento de Mineralogía y Petrología de la Universidad de Granada. Las muestras se analizaron utilizando el método de polvo cristalino desorientado, para lo que previamente debieron ser molidas en mortero de ágata hasta tamaño inferior a 0,053 mm. Una vez realizados los difractogramas se procedió a su interpretación cualitativa, realizándose igualmente un análisis semicuantitativo, en el que se obtuvieron los porcentajes relativos de unos minerales con respecto a otros, con un margen de error de \pm 5\% (SEBASTIÁN, 1996).

Para el estudio por Microscopía Óptica, se prepararon láminas delgadas de muestras inalteradas de los distintos tipos de morteros de unión que se encontraron en el muro. Las muestras del relleno interior del muro (R), debido a su friabilidad, no mostraron la suficiente dureza como para realizar con ellas láminas delgadas. Se elaboraron láminas sin cubrir para la realización de posibles tinciones selectivas de carbonatos, si fuera preciso. Todas las láminas delgadas se estudiaron de forma detallada en un microscopio petrográfico de luz polarizada marca Zeiss, con equipo fotográfico incorpo- 
rado, perteneciente al Departamento de Edafología de la Universidad de Granada. En este estudio se realizó la caracterización mineralógica de las muestras, junto con su descripción micromorfológica, aportando datos referentes tanto a las propiedades físicas de los distintos constituyentes (porosidad, tamaño y morfología del árido, etc.), como al estado de conservación de las muestras, mediante la aparición o no de diferentes rasgos característicos.

El Análisis Granulométrico necesitó de la disgregación previa de la muestra en medio acuoso. Las fracciones menores de 50 micras se separaron por sedimentación, previa dispersión y extracción de alícuotas correspondientes (método de la pipeta de Robinson). Las partículas mayores de 50 micras se separaron por cascada de tamices. Las fracciones separadas y su denominación, según la clasificación edafológica, se detallan en la Tabla 2.

Tabla 2. Clasificación granulométrica utilizada

\begin{tabular}{|c|c|}
\hline FrACCION & TAMAÑO (MM) \\
\hline Grava & $>2$ \\
\hline Arena & $2-0,05$ \\
\hline Limo grueso & $0,05-0,02$ \\
\hline Limo fino & $0,02-0,002$ \\
\hline Arcilla & $<0,002$ \\
\hline
\end{tabular}

\subsection{Materiales constitutivos (Piedra, morteros de unión $y$ relleno interior de muro)}

La roca se clasifica como una caliza micrítica (de grano muy fino) con bioclastos (granos de origen biológico tales como espículas de erizo, foraminíferos, etc). Abundan los granos no esqueletales denominados "pellets" que aparecen como partículas esféricas de carbonato microcristalino. La matriz que se encuentra rellenando los huecos entre los granos es también micrítica y se detectan algunas recristalizaciones de esparita (cristales de calcita apreciables al microscopio) en el interior de algunos poros.

El estado de conservación de los fragmentos pétreos estudiados no es bueno. Aparece un sistema de fisuración paralelo a la superficie, relacionado con las condiciones meteorológicas y principalmente con los cambios bruscos de temperatura. También aparecen fisuras transversales a las anteriores y que fragmentan la roca en profundidad.

Junto con esta alteración física, numerosos puntos de la roca se ven afectados por procesos de alteración química, que aprovechan el sistema de fisuración establecido para actuar. En este sentido, las costras de suciedad y eflorescencias salinas son los rasgos de alteración más frecuentes, apareciendo en algunos puntos una matriz coloreada en tonalidades rojizas-marrones, producido por la liberación química de minerales de la arcilla y óxidos de hierro que, en forma de impurezas, estaban contenidos en la roca caliza original.

Los resultados del estudio por microscopía óptica de polarización de los dos tipos de morteros de unión analizados son similares en ambos casos, e indican que está compuesto principalmente por material carbonatado (calcita y dolomita) y cuarzo, acompañando a éstos otra serie de minerales en cantidades poco significativas (Lámina I).

El árido está compuesto predominantemente por granos de dolomía y caliza (en forma de calcita esparítica y calcita bioclástica), también aparecen otras especies minerales tales como cuarzo, feldespato y plagioclasa que en conjunto no superan el $20 \%$ del total del árido. Los tamaños son muy heterométricos, indicando una pobre selección de tamaños, aunque se aprecia un cierto predominio de las fracciones menores a los 0,05 milímetros. Los granos de calcita aparecen alterados, pero la presencia de minerales tales como el feldespato y la plagioclasa (disueltos parcial o casi totalmente en la mayoría de los casos) indican un menor grado de alteración en el mortero MI, donde estos minerales han desaparecido casi por completo.

El aglomerante utilizado en este tipo de morteros fue la cal. La cementación con los granos del árido fue buena en su momento, ya que en muchas zonas los bordes del árido aparecen 
bien incluidos en la matriz. Actualmente están moderadamente alterados, detectándose la presencia relativamente frecuente de minerales de la arcilla "manchando" esta matriz carbonatada. De forma aproximada, la razón árido/aglomerante podría situarse alrededor de 3/l.

Presentan estos morteros una porosidad que se sitúa entre el 15-20\%. Por su elevado grado de alteración, esta porosidad debería ser mayor, pero no lo es debido a que numerosos poros y fisuras están rellenos por recristalizaciones de calcita.

Predomina la porosidad de disolución de granos. Aunque aparece un tipo de poro muy característico como son las vesículas, formadas por la presencia de burbujas de aire atrapadas durante la cementación, pudiendo indicar una elevada velocidad de fraguado (Láms. 2 y 3).

También aparecen microfisuras localizadas en distintos puntos de la matriz, que afectan igualmente a las uniones grano-matriz. Los tamaños de poro mayores coinciden con la disolución de granos mayores $(>0,5 \mathrm{~mm}$ ), las vesículas muestran un diámetro predominante en torno a los $0,25 \mathrm{~mm}$, mientras que las microfisuras son las de menor tamaño de poro $(<0,002 \mathrm{~mm})$.

En cuanto al estado de conservación, la presencia de determinadas alteraciones nos alerta sobre la acentuación de los procesos de degradación con el tiempo, por lo que se destacan los siguientes rasgos: A) Recristalizaciones de calcita tanto en el interior de los poros, como en la superficie de granos minerales con distintos tamaños de grano, poniendo de manifiesto la sucesión de varias etapas de crecimiento cristalino. B) Disolución parcial y reemplazamiento de calcita en granos del árido, creando porosidad intragranular de distinto tamaño. C) Halos de reacción de material no carbonatado producidos en torno a fisuras o al rededor granos minerales. D) Elevada degradación del aglomerante con baja proporción en cal y rico en arcilla, puesta de manifiesto por la presencia de fisuración y disoluciones parciales. E) Presencia de criptoflorescencias salinas en el interior de poros con un efecto deteriorante mucho más elevado que el de las eflorescencias superficiales, ya que el crecimiento de cristales en el interior de espacios limitados origina tensiones que afecten a la estabilidad del material.

El material utilizado como relleno interior de muro posee una escasa o nula coherencia, y se presenta como una mezcla muy heterogénea de partículas finas y gruesas. Entre los fragmentos mayores aparecen trozos de tejas, ladrillos y cerámica, empleados como carga y "relleno" de esta masa interior. El material fino parece tener una composición mineralógica similar a la de los morteros descritos en el apartado anterior, y el aglomerante empleado es cal igualmente, aunque aportado en cantidades muy bajas; en este sentido, la razón árido/aglomerante es mucho menor que en el caso de los morteros, pudiendo situarse en valores inferiores a 1/5. La baja proporción de cal, junto con las elevadas cantidades de partículas de diferente tamaño y composición, explican la escasa coherencia de este material.

El análisis granulométrico de los materiales descritos revela grandes diferencias entre ellos. Como se aprecia en la Figura 2, la fracción dominante en el material utilizado como relleno interior de muro (R) es la de mayor tamaño, mientras que los dos morteros de unión analizados también presentan diferencias texturales importantes, seguramente influenciadas por su grado de alteración.

\subsection{Productos de alteración (sales y costras)}

La problemática de este tipo de productos de alteración no sólo concierne a la estética del monumento, sino que suponen una degradación de los materiales constitutivos y pueden generar graves problemas en la conservación a largo plazo de la mayor parte de los edificios históricos. Dependiendo del grado de deterioro alcanzado se puede llegar a ver afectada incluso la estabilidad estructural de partes del monumento, por lo que la necesidad incorporación de materiales nuevos es inevitable en muchos casos. 
Uno de los principales problemas de las sales es su movilidad. Se consideran como sales solubles aquellas que tienen una solubilidad igual o superior a los 2,4 g/l. Esta solubilidad está controlada fundamentalmente por la temperatura y la humedad. Es decir, a temperaturas altas aumenta la cantidad de sales que puede haber en disolución, mientras que a temperaturas bajas esta cantidad disminuye. De igual forma, la cantidad y circulación de agua en el material condicionan la presencia de sales. En medios bien drenados las sales se pierden por lavado, mientras que en medios con drenaje deficiente, la concentración de sales en disolución puede llegar a superar su límite de solubilidad y provocar su precipitación. Por todo esto, la aparición de sales es muy variable y está ligada tanto a variaciones estacionales como diarias, viéndose afectada claramente por cambios de humedad y temperatura, orientación con respecto al sol, proximidad al terreno, etc.

Otro inconveniente importante de las sales es que cristalizan con tamaños relativamente grandes, por lo que si se forman en el interior de espacios limitados (poros) producen tensiones importantes que pueden ocasionar daños en la estabilidad estructural del material. Además, algunas de ellas, pueden sufrir cambios de volumen debidos a cambios de fase por procesos de hidratación-deshidratación. Por todo esto, es importante distinguir entre eflorescencias, cuando la cristalización de sales se realiza en la superficie del material, y criptoflorescencias, cuando ésta se realiza en el interior del mismo. Evidentemente el efecto disruptivo de las segundas es mucho más elevado que el de las primeras $y$, en cualquier caso, están consideradas como uno de los agentes deteriorantes más importantes en edificios de interés histórico-artístico (ARNOLD y ZHENDER, 1989).

En el caso de muralla estudiado, se recogieron eflorescencias salinas en diversos puntos de la superficie de la muralla. Para evitar procesos de deshidratación, las muestras tomadas se conservaron en recipientes herméticos y se analizaron rápidamente mediante difracción de rayos $X$. Se describen como eflorescencias salina de color blanquecino, localizadas sobre los fragmentos de rocas y entre las descamaciones de éstas. El estudio por difracción de rayos $x$ indicó que la composición dominante de estas sales es yeso $\left(\mathrm{CaSO}_{4} \cdot 2 \mathrm{H}_{2} \mathrm{O}\right)$. Sus recristalizaciones internas han provocado tensiones que son las responsables, entre otras causas, de los efectos de descamación de las rocas del muro de mampostería.

Las costras de suciedad superficial (SUC) aparecen como una capa producida por procesos de recristalización que recubre parte de la superficie de la muralla, de color negro o gris oscuro, y de superficie irregular. En el estudio mediante difracción de rayos $x$ se obtuvo que su composición es de Calcita (85\%) y Yeso (15\%). Los procesos que han participado en la génesis de estas costras han sido la disolución, el lavado y la precipitación del material del soporte (tanto la roca como el mortero) originando una costra fundamentalmente carbonatada que recubre parte del paramento. El principal agente que ha propiciado su formación ha sido el agua atmosférica, prácticamente inevitable en un monumento situado a la intemperie. Por otra parte, la presencia de yeso, indica en este caso la participación conjunta de procesos de contaminación que provocan la transformación de $\mathrm{SO}_{2}$ atmosférico en ácido sulfúrico que ataca las rocas calcáreas y el mortero carbonatado, produciendo la liberación de calcio y la formación de yeso. La actuación de la contaminación atmosférica (especialmente del tráfico rodado) parece ser relativamente intensa debido a la proximidad de vehículos al inmueble.

Aparecen también otro tipo de costras (SUC_VEG), que aparecen como una capa de recristalización de color negro o grisáceo, similar a la anterior, que recubre parte de la superficie de la muralla pero que se asocia a las zonas donde hay vegetación y a las partes inferiores del muro. En el estudio mineralógico por difracción de rayos $\times$ se obtuvo una composición de Calcita (25\%) y Yeso (75\%). La morfología, estructura y origen de esta costra de suciedad es el mismo que el de la costra estudiada anteriormente, pero aparecen claras diferencias cuantitativas en cuanto a las especies minerales dominantes. 
En este caso es el yeso la especie mayoritaria, lo que se puede explicar por los efectos de una intensa contaminación atmosférica, puesta de manifiesto en este tipo de costra de forma mucho más acusada por la presencia de vegetación. En estas partes de la muralla, la retención de humedad es mucho mayor, así como la liberación de $\mathrm{CO}_{2}$ por parte de las plantas, lo que contribuye de forma mucho más acusada a la disolución de la roca caliza y, por tanto, a una mayor liberación de calcio. La elevada proporción de yeso indica que la cantidad de $\mathrm{SO}_{2}$ proveniente de la contaminación también es elevada. Este hecho coincide con la alta circulación de automóviles por las inmediaciones de la muralla. Este tipo de recristalizaciones representan un problema no solamente estético, sino también de deterioro, ya que pueden provocar la arenización de la roca infrayacente.

\section{ESTADO DE CONSERVACIÓN Y PATOLOGÍAS}

Aun siendo un reducido tramo el restaurado, hay que destacar la absoluta falta de continuidad del lienzo de muralla, que ha quedado englobado en un conjunto de edificaciones en los casos más favorables, siendo destruido en los más desafortunados, aquí la muralla fue sesgada junto al torreón cilíndrico para poder facilitar el acceso a una cochera.

Por otro lado, la acumulación de materiales y terreno en la base de los muros ha modificado las cotas originales y alterado su configuración. Esta circunstancia hace que la percepción de esta zona de la muralla no sea posible dado que al carecer de un entorno circundante libre, la visualización de la misma no es completa, sin mencionar los vehículos que ocupan el espacio que se extiende delante, aparcando justo al lado del lienzo, añadiendo al choque visual los consiguientes problemas de contaminación y deterioros que ello acarrea.

Los principales problemas que presentaba el tramo de muralla intervenido se derivaban del factor que a su vez había permitido su conservación, ya que si bien dicho tramo se encontraba oculto y transformado por varias edificaciones adosadas, éste hecho a su vez había supuesto su mantenimiento, al haberlo integrado como elemento constructivo en los edificios.

El aprovechamiento de las estructuras edilicias anteriores ha sido habitual desde tiempos remotos. Este hecho tenía una doble intención, ya que suponía un ahorro para los nuevos ocupantes, marcando al mismo tiempo un carácter hegemónico sobre la anterior cultura.

El lienzo de muralla en cuestión había permanecido oculto tras diversas edificaciones sin ningún valor histórico, hasta época reciente, cuando se han conseguido demoler algunos de estos edificios cuyo estado era en cualquier caso ruinoso. Únicamente el torreón cilíndrico permanecía semi visible, aunque también había sido objeto de invasiones por parte de la vivienda contigua, que ocupaba su parte superior con una terraza cerrada con una barandilla de hierro sobre un antepecho de ladrillo, desde la que sobresalía a modo de bandera una antena de televisión.

Al liberar el paramento de la muralla de las estructuras anexas se evidenciaron las heridas causadas a lo largo de diversas etapas (Lám. 6). Las más graves habían horadado el muro para abrir tres huecos. Uno situado a nivel del suelo actual, atravesaba el grueso del muro para abrir una puerta que conecta ambos lados de la muralla, mientras que los otros dos la perforan en la parte que correspondería a la primera planta de las viviendas adosadas. Claramente visibles permanecían las huellas de este forjado, marcando una línea de puntos continua en todo el tramo.

Hay que considerar que las pérdidas de material en las coronaciones de los muros favorecen los procesos de desintegración de los lienzos de muralla, alterando la geometría de los mismos. La coronación que tuviera la muralla en su primitiva construcción se encuentra hoy reducida en este tramo en altura y limitada por su uso habitable, apareciendo en la parte superior una solería, muestra de su ocupación indebida (Lám. 7). 
A nivel estético en la piel más externa, la fábrica de mampostería estaba tapada por revestimientos diversos, cementos, enjalbegados, morteros de agarre de azulejos, restos de chimeneas, etc., convirtiendo la superficie de la muralla en un "mosaico" de materiales y texturas que ocultaban la verdadera identidad del elemento constructivo (Lám. 8).

Además de estas alteraciones detectadas una vez habían sido derribadas las edificaciones adosadas, iniciados los trabajos de limpieza fueron apareciendo otras actuaciones que reflejaban reconstrucciones parciales del muro realizadas mediante fábrica de ladrillo y morteros y piedras de distintas composiciones, ejecutadas todas ellas sin ningún criterio y que no hacían sino continuar transformando la adecuada valoración perceptiva del conjunto, además de favorecer los procesos de degradación del elemento, al debilitar puntualmente la fábrica original e introducir materiales como el yeso o el cemento que por sus propias características compositivas no hacen sino favorecer los procesos de alteración de las materiales existentes.

Por otro lado, la presencia de plantas de porte medio enraizadas en las juntas del muro, (Lám. 9) favorecía la entrada de agua en su interior, quedando retenida por las raíces, con el consiguiente peligro de estabilidad de la fábrica, debido al paulatino aumento de volumen de las raíces y la disolución parcial del carbonato cálcico provocado por la actividad del $\mathrm{CO}_{2}$ generado por las plantas.

A los problemas causados por factores externos de alteración y que afectan de un modo generalizado a todo el conjunto, hay que considerar otros que son propios de las características intrínsecas de los materiales constitutivos de la muralla, anteriormente descritos con detalle. Sólo cabe puntualizar que en este caso y tipología constructiva, las zonas más débiles y por tanto más fácilmente degradables corresponden al mortero de agarre de la mampostería, que aparece en numerosas zonas disgregado, con pérdida de cohesión y desaparecido, estando las alteraciones de la piedra localizadas de forma más puntual.
Pese a las patologías mencionadas, la muralla en el tramo intervenido no presentaba problemas a nivel estructural, siendo las alteraciones estéticas y funcionales las más acusadas, habiendo llegado incluso a perder su identidad como elemento monumental y fuente histórica de primera magnitud.

\section{INTERVENCIÓN}

Previo a la intervención directa sobre el tramo de muralla de la Carrera de Jesús se llevaron a cabo una serie de estudios y trabajos, los principales de ellos expuestos anteriormente, cuyo objetivo era obtener los datos precisos para acometer la obra con el rigor requerido, tanto en lo que a materiales y técnicas constructivas se refiere, como a los criterios y filosofía a seguir en el proceso.

La pauta general y fundamental que ha marcado la línea de actuación ha sido la de la conservación y respeto por el elemento, limitando las nuevas aportaciones de materia exclusivamente a las cuestiones consideradas precisas para garantizar la estabilidad futura del tramo de muralla. En todos los casos, estas adiciones han quedado claramente definidas y diferenciadas de lo que es el original, estando no obstante debidamente integradas en sus diferentes aspectos en el conjunto de la muralla. Así mismo, se buscó la compatibilidad y durabilidad de los materiales añadidos, evaluando la eficacia de los tratamientos llevados a cabo.

Han sido cuatro los procesos principales que se han planteado y ejecutado, definiendo unos objetivos y parámetros concretos en cada caso: limpieza, consolidación, restitución y protección.

La limpieza engloba toda una serie de trabajos encaminados a liberar a la fábrica de elementos añadidos al original, revestimientos y morteros superpuestos y suciedad de diversa índole que supongan una distorsión estética o material.

Con esta premisa, se acometieron diferentes tareas, comenzando por el derrumbe de 
aquellas edificaciones adosadas en las que afortunadamente se pudo llegar a dar este paso.

Una vez recuperado en la medida que fue posible el espacio robado anteriormente al elemento, se suprimieron los restos que permanecían de las antiguas edificaciones que habían estado adosadas, para recuperar así los volúmenes y el paramento original. Ello se realizó mediante picado selectivo o desplacado de los revestimientos, teniendo sumo cuidado de no afectar al muro primitivo, limpiando igualmente los enjalbegados, costras y suciedad existente.

La solería que aparecía en la coronación fue también eliminada, así como lógicamente la antena de televisión instalada en el torreón y los cables que se pegaban a los muros.

Se debatió sobre la conveniencia o no de eliminar el antepecho de ladrillo que reconstruía la forma en la parte alta del torreón, dado su fuerte impacto visual, no obstante se realizaron catas para sondear la existencia de fábrica de mampostería tras él, y al no existir ésta y puesto que se trataba de una fábrica consolidada en buen estado, se consideró conveniente dejarlo.

Las plantas fueron tratadas por medio de la aplicación de un herbicida con doble acción curativa y de efecto permanente, evitando de este modo en la mediad de lo posible la nueva proliferación de vegetación.

Con los procesos de consolidación se devolvió a la muralla la estabilidad desaparecida puntualmente, que, como se dijo antes, afectaba más a los materiales en sí mismos que a su capacidad estructural.

En este procedimiento se trataron las juntas de mortero, saneando, eliminando y cepillando el material que se encontraba en mal estado, añadido o suelto hasta la profundidad necesaria para alcanzar el material en buen estado.

Posteriormente se procedió al rejuntado de la totalidad del paramento en todas aquellas zonas donde se hacía necesario, ya que durante la fase anterior de saneado de juntas se habían mantenido aquellas consideradas originales y que se encontraban en perfecto estado de conservación. Para el sellado de juntas se empleó un mortero de cal y árido seleccionado, cuya elección en cuanto a composición, granulometría y colorimetría se refiere estuvo basada en los resultados del estudio analítico previamente realizado. No obstante, fueron ensayados varios morteros in situ antes de tomar la decisión última, al objeto de comprobar las características del mortero puesto en obra, trabajando su textura y acabado.

En todos los casos este relleno de juntas quedó rehundido respecto a los sillares originales, marcando con nitidez la fábrica y materiales originales.

Algunos sillares de piedra que mostraban cierta disgregación y exfoliaciones, fueron consolidados mediante la aplicación en superficie de un producto consolidante, silicato de etilo en disolución, repitiendo la aplicación en varias etapas hasta obtener la idónea estabilidad del material pétreo.

La restitución de material fue quizá la tarea más debatida por tratarse de aportes realizados sobre la fábrica existente que permanecía como original. No obstante, pese a considerar estas reintegraciones como mínimas y limitarlas a zonas precisas, había casos en los que se hacían imprescindibles para poder garantizar el adecuado mantenimiento de la estructura muraria.

Así pues, aparte del rejuntado necesario para la consolidación del elemento, se requería tratar los huecos dejados por las anteriores construcciones, suponiendo además de zonas de debilidad estructural, rupturas de la configuración visual del conjunto.

Todas las oquedades, tanto la de los huecos de alacenas como las de los forjados o desprendimientos, independientemente de su tamaño, fueron restituidas con mortero de cal, aplicado en varias capas dependiendo del grosor del hueco, quedando siempre rehundido con 
respecto a los límites de la oquedad, permitiendo de este modo que la lectura del la fábrica original quedara perfectamente clara y definida, marcando al mismo tiempo las huellas de las diferentes circunstancias que había sufrido el tramo de muralla, pudiendo así leer e interpretar la historia vivida por el elemento.

Realizando estas restituciones matéricas con mortero, frente a la posibilidad de rehacerlas con mampostería, no se dio la opción de caer en ningún momento en una posible confusión o engaño en cuanto a la fábrica original se refiere.

El antepecho de ladrillo de la torre recibió un tratamiento más acorde con el conjunto, revistiéndolo con un acabado de mortero fratasado, empleando el mismo material que se venía utilizándose en el resto de la obra, constituyéndose así en una huella más de su historia.

Como último tratamiento se llevó a cabo una protección del tramo de muralla sobre el que se había trabajado. Es imprescindible una adecuada protección del elemento intervenido, al objeto de garantizar su conservación en el tiempo, aislándolo dentro de lo posible de los agentes de alteración que le afecten.

Se realizaron dos procedimientos protectores. Uno que afectaba a la coronación del tramo de muralla y otro extensible a la totalidad de su superficie.

En coronación, eliminada la solería existente, se aplicó en toda la superficie un mortero hidrófugo con pendiente hacia en torreón, donde se colocó un desagüe formado por una teja que vertía las aguas hacia el exterior en el lateral donde se abre la cochera.

En toda la superficie se aplicó un producto hidrofugante a base de siloxanos que permitiera la transpiración de los materiales, impidiendo la entrada de agua en su interior.

\section{CONSIDERACIÓN FINAL}

No debe perderse de vista la consideración de que el tramo de muralla restaurado se trata precisamente de un fragmento cuya identidad y significación sólo cobrará su verdadero sentido dentro del conjunto de las murallas de la ciudad, por tanto, es fundamental la intervención en el espacio circundante de la muralla, liberándolo de las construcciones anexas y realizando un tratamiento del entorno, para poder cualificar y valorar la muralla en su dimensión real.

Pese a los esfuerzos realizados, no ha podido liberarse la totalidad del tramo de muralla. Quede ahí oculto bajo etapas posteriores, y sirva la presente recuperación y puesta en valor sobre el tramo intervenido como muestra histórica, social y cultural del pasado de la ciudad.

\section{AGRADECIMIENTOS}

Agradecer a la Dra. Carmen Pérez Miñano su interés en la realización de este proyecto

\section{BIBLIOGRAFÍA}

Arnold, A. y Zehnder, K. 1989. Salt weathering on monuments. Actas del ler Simposio Internationale: "La conservatione dei monumenti nel bacino del Mediterraneo", Bari. p. 31-58.

Berges, L. 1986. Un tramo de la muralla sur de Jaén. Rv. Senda de los huertos, 7: 55-66.

Castillo Armenteros, J.C. y Marín García, M. 1999. Informe técnico sobre los trabajos de excavación y consolidación arquitectónica en el Castillo de Santa Catalina (Jaén). En: Anuario arqueológico de Andalucía 1994. Ed. Consejería de Cultura de la Junta de Andalucía. p. 259-270.

Pérez Miñano, C. 2003. La imagen de la ciudad de Jaén. (Ed. Excmo Ayuntamiento de Jaén).

Sebastián, E. 1996. Interés de la Difracción de Rayos X (DRX) en la conservación del patrimonio cultural. En: Técnicas de diagnóstico aplicadas a la conservación de los materiales de construcción en los edificios históricos. (Ed. IAPH). p. 8-II. 


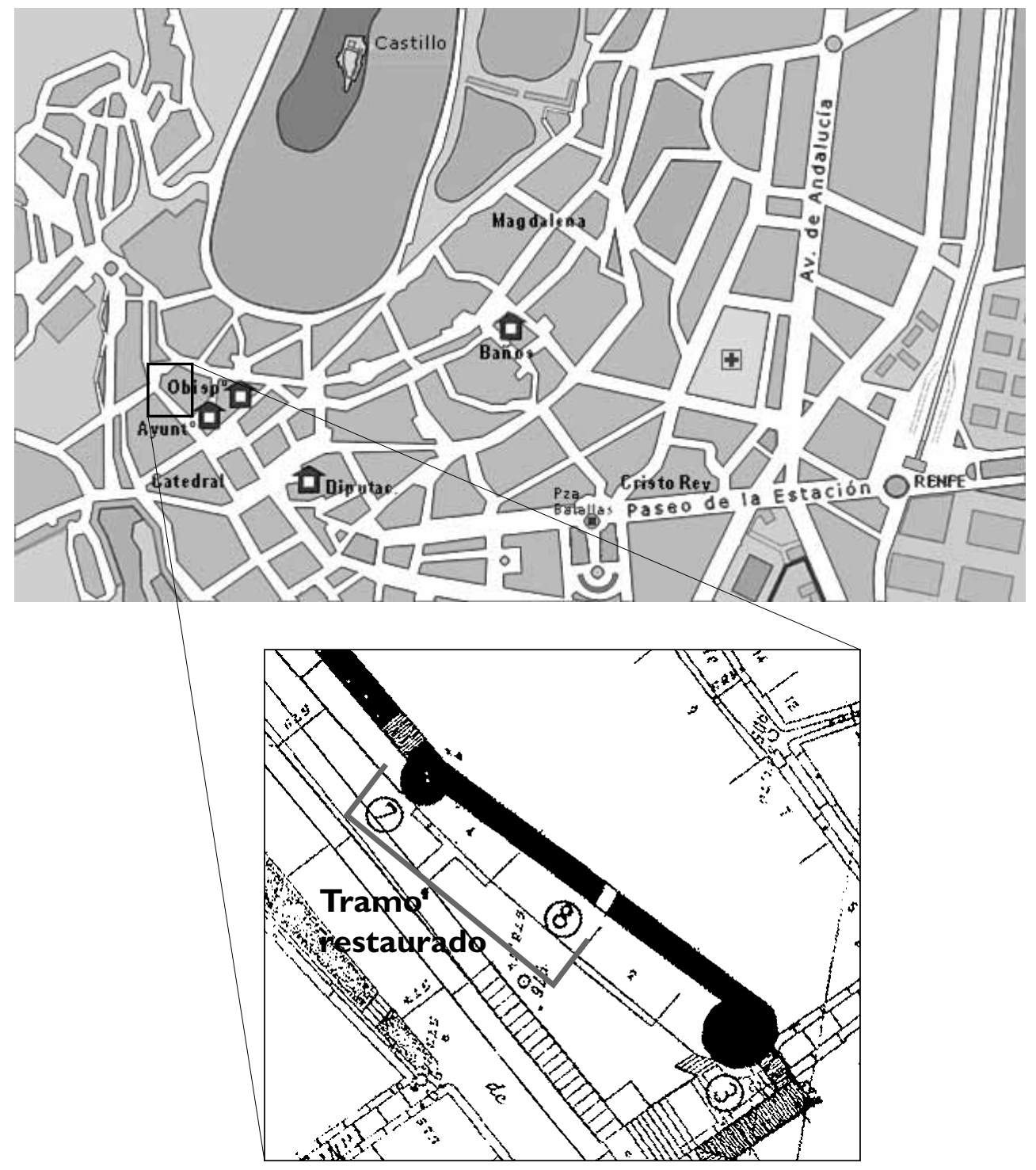

Figura I. Localización del tramo de muralla restaurado.

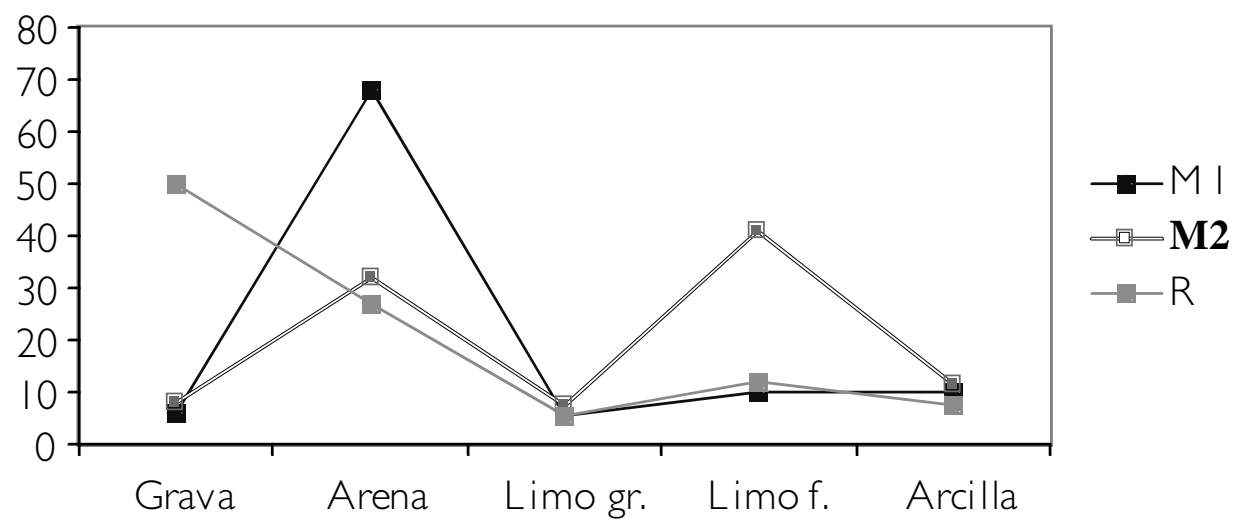

Figura 2. Distribución granulométrica de las muestras analizadas. 


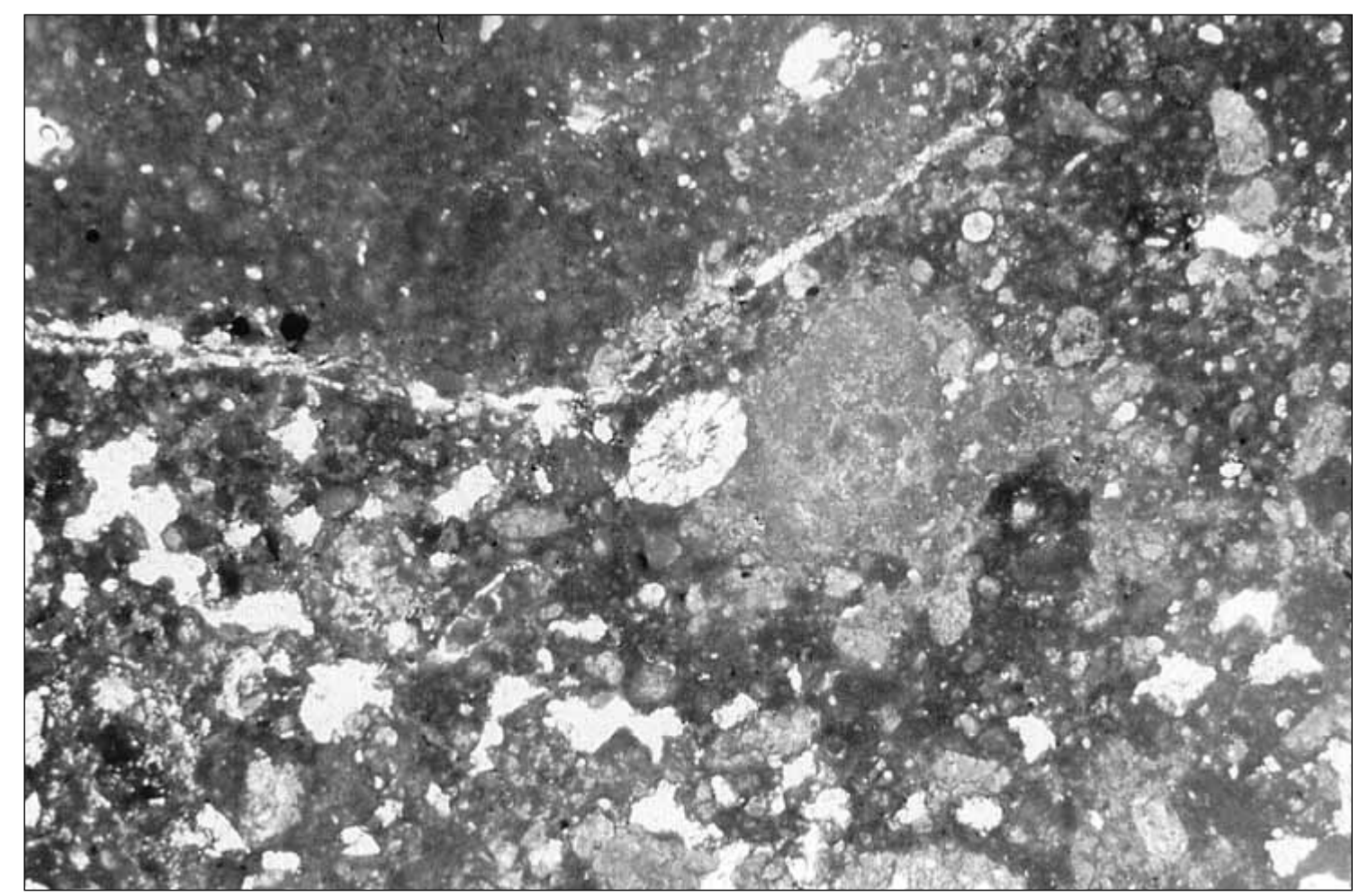

Lámina I. Vista general MI (25 aumentos, nícoles paralelos)

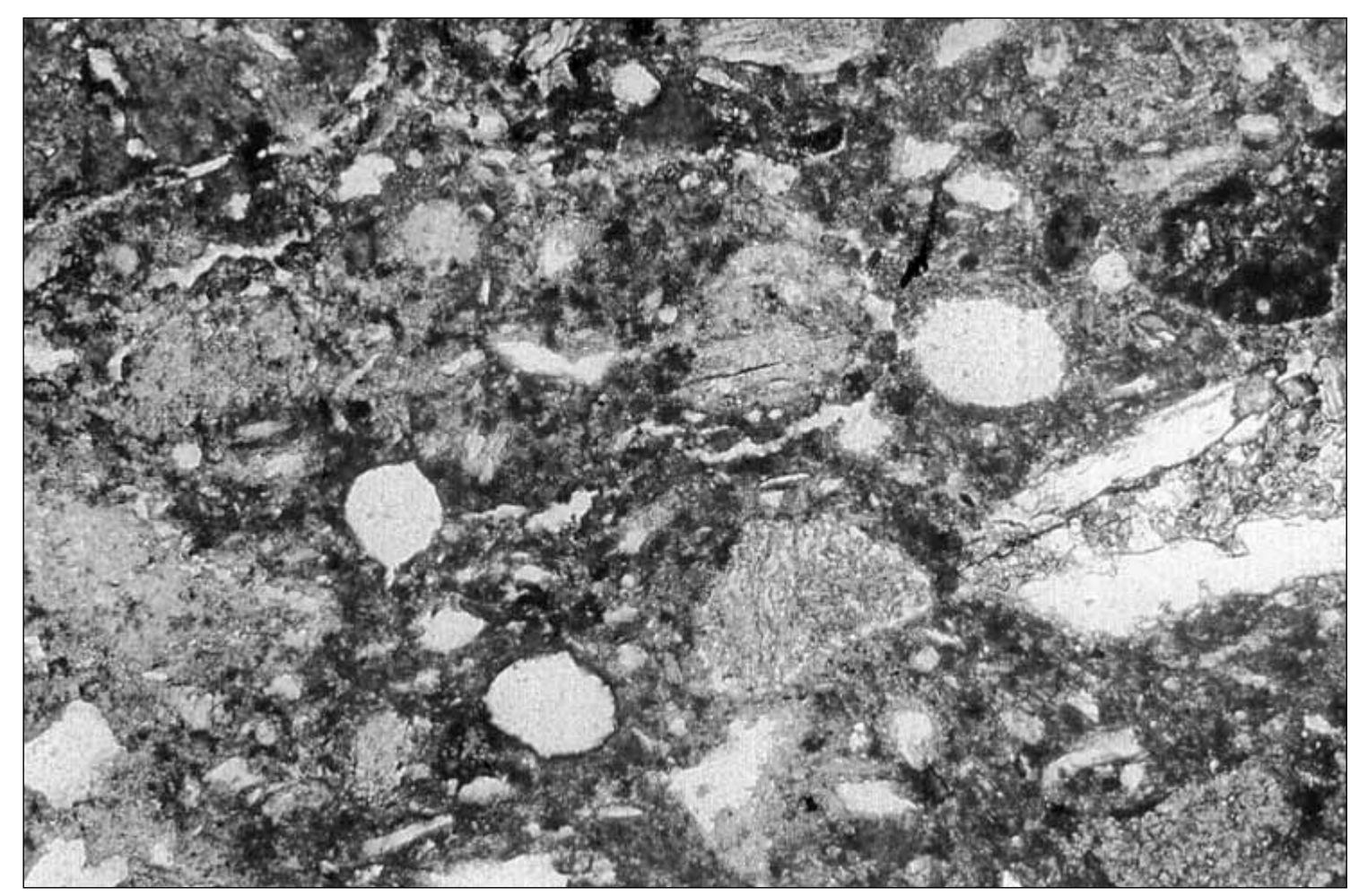

Lámina 2. Vista general M2. (25 aumentos, nícoles paralelos). 


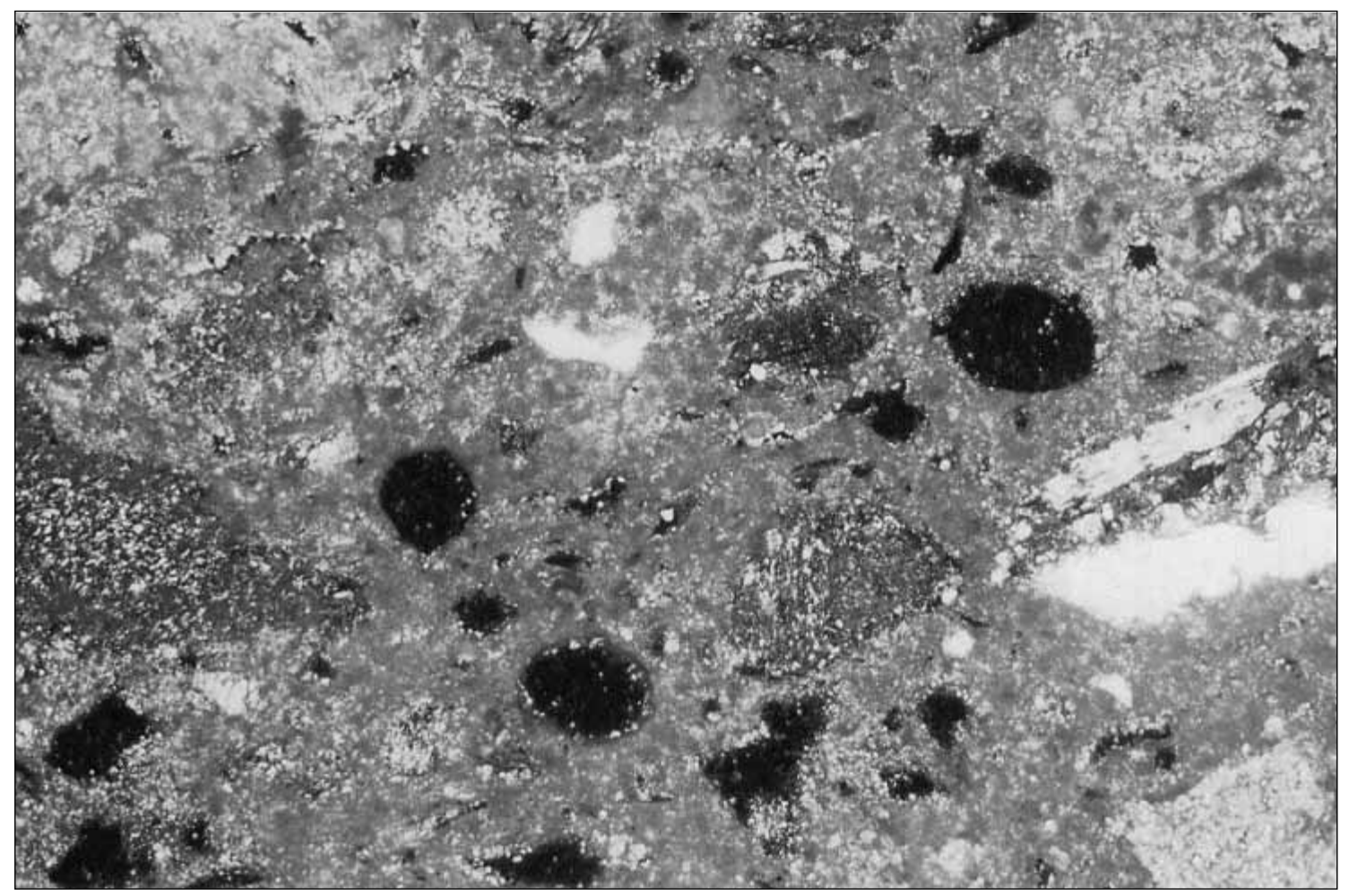

Lámina 3. Vista general M2. (25 aumentos, nícoles cruzados).

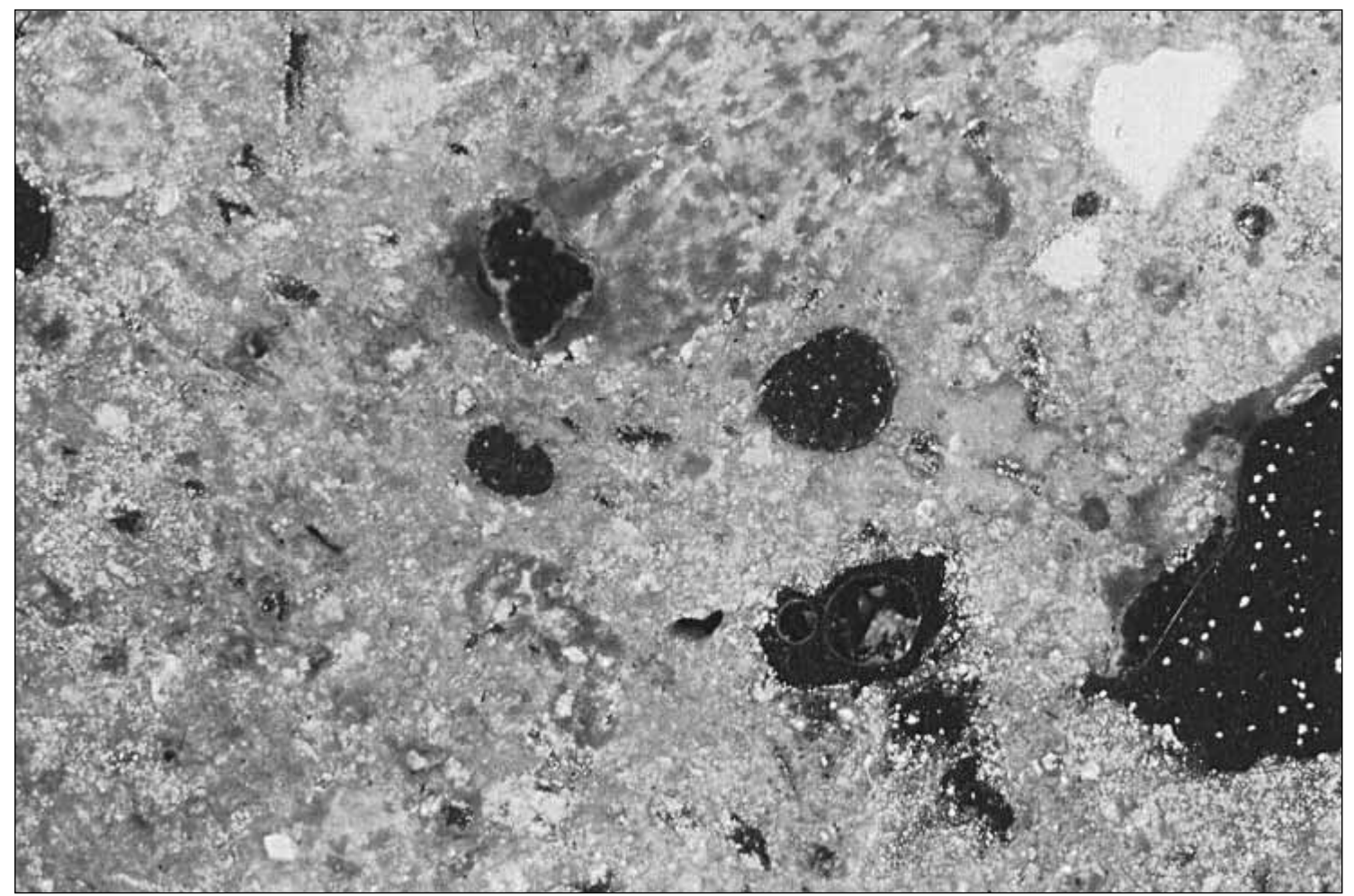

Lámina 4. Detalle MI (50 aumentos, nícoles cruzados). 


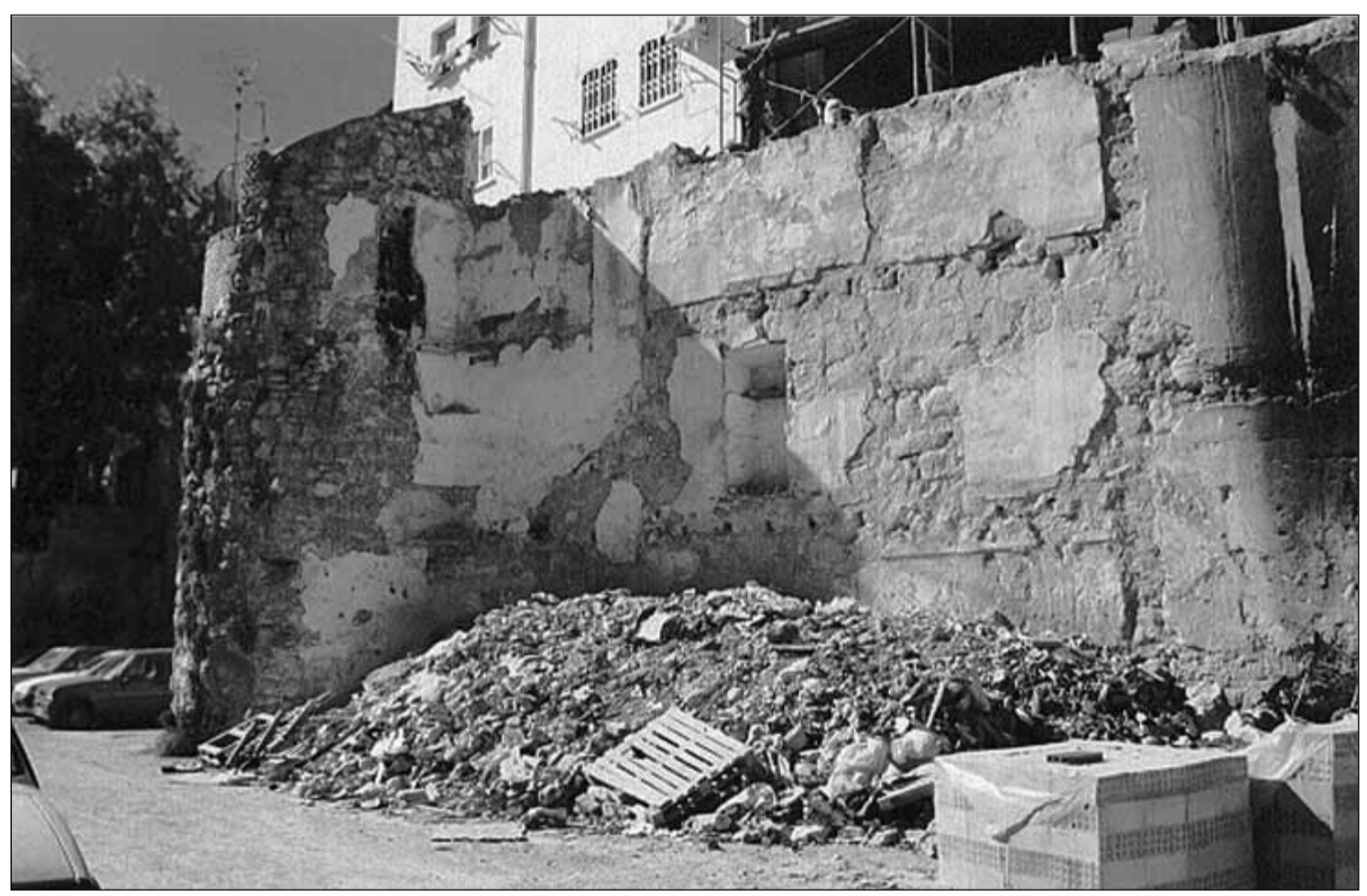

Lámina 5. Estado previo a la restauración.

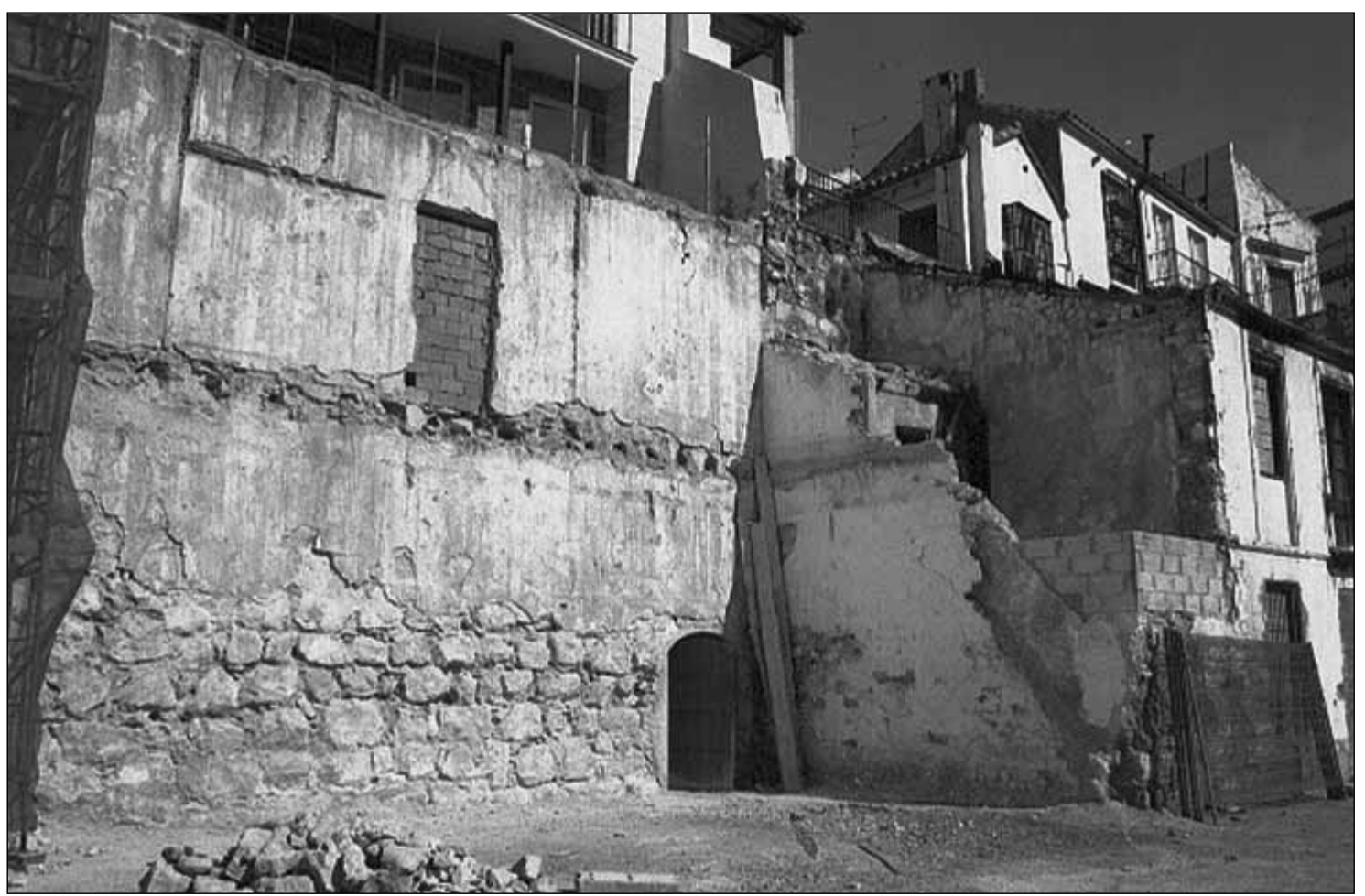

Lámina 6. Huella de antiguas edificaciones adosadas 


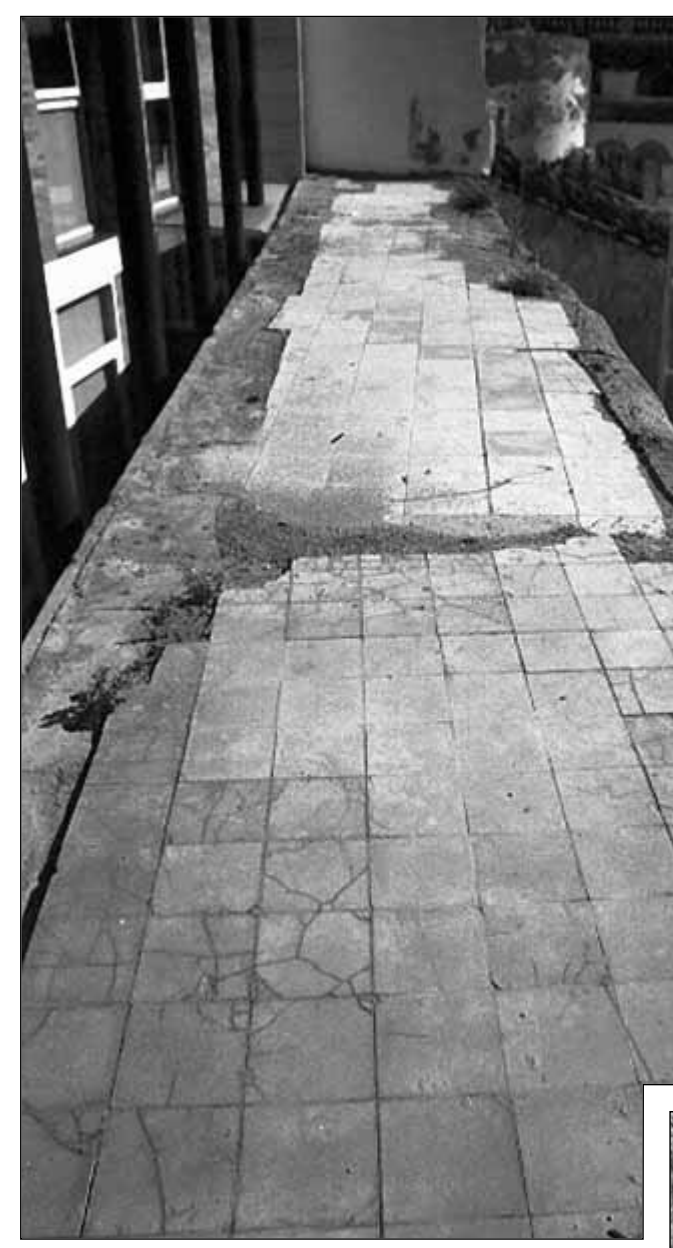

Lámina 7. Solería en coronación.

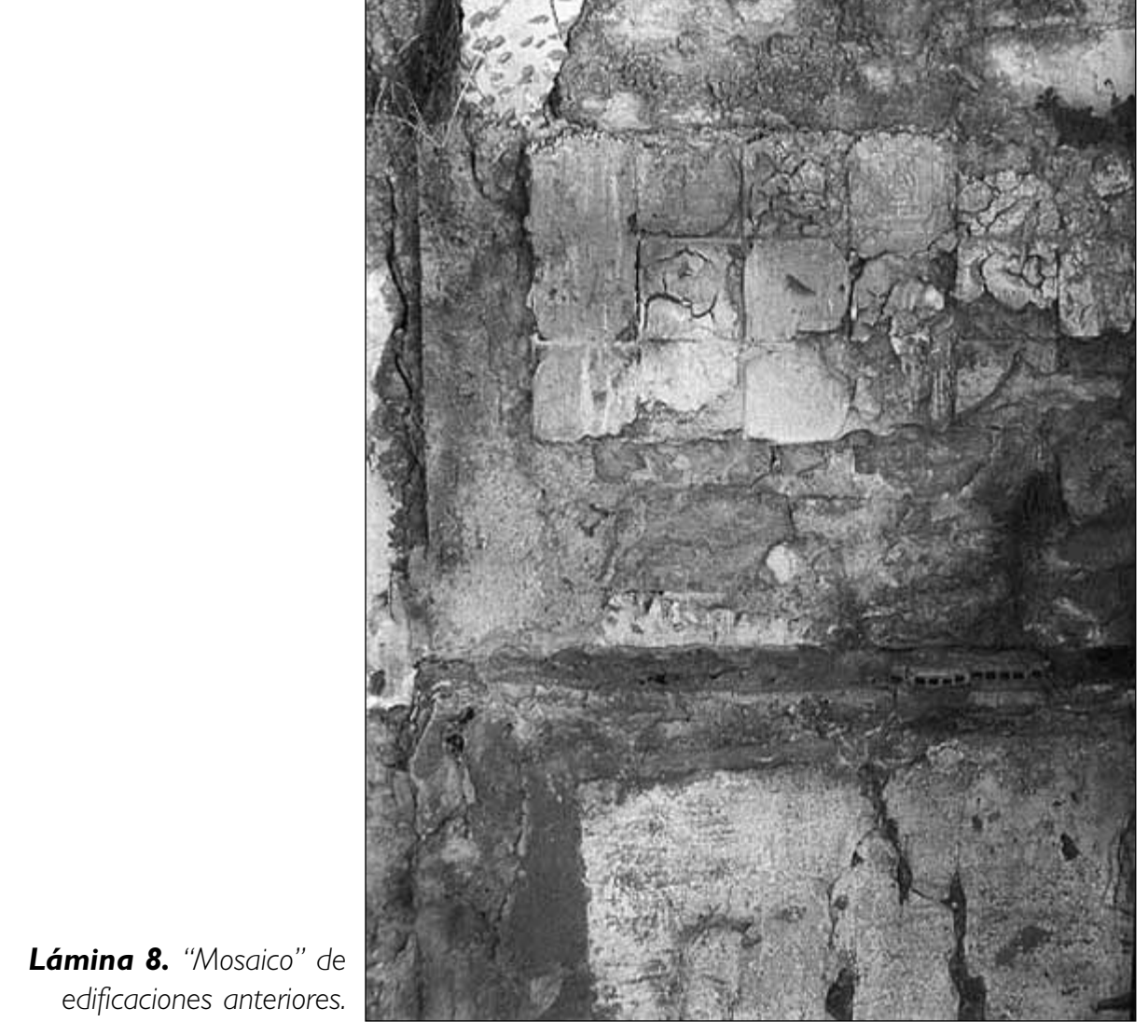




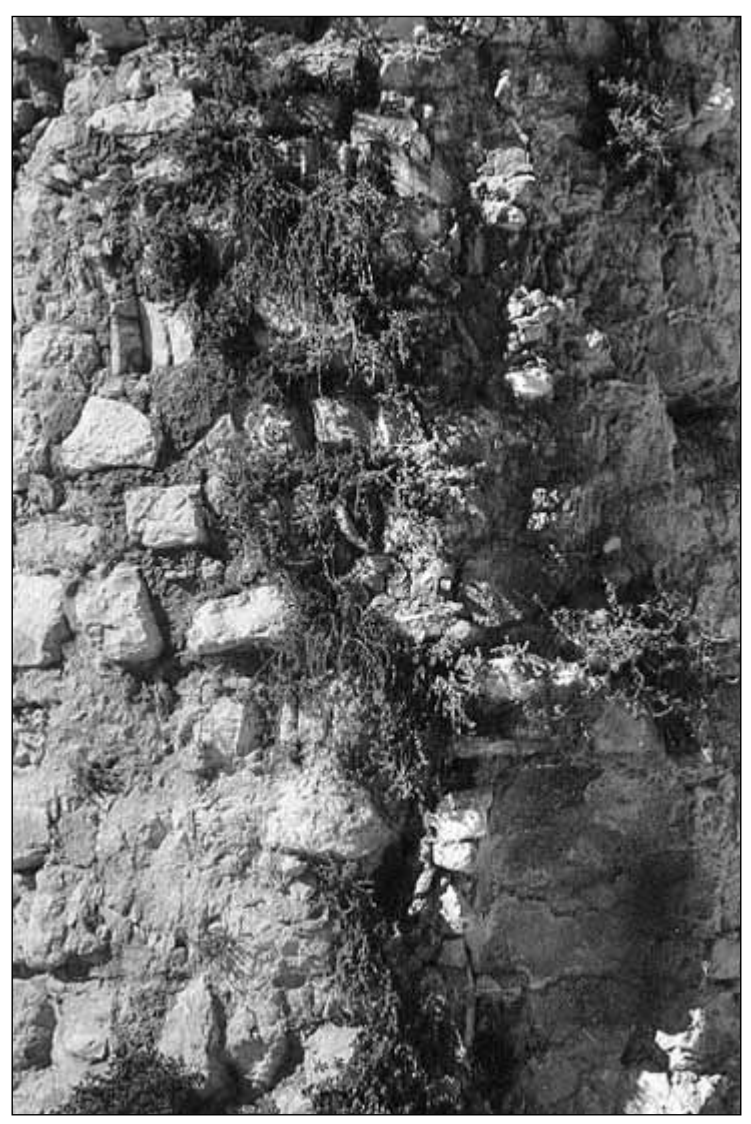

Lámina 9. Vegetación.
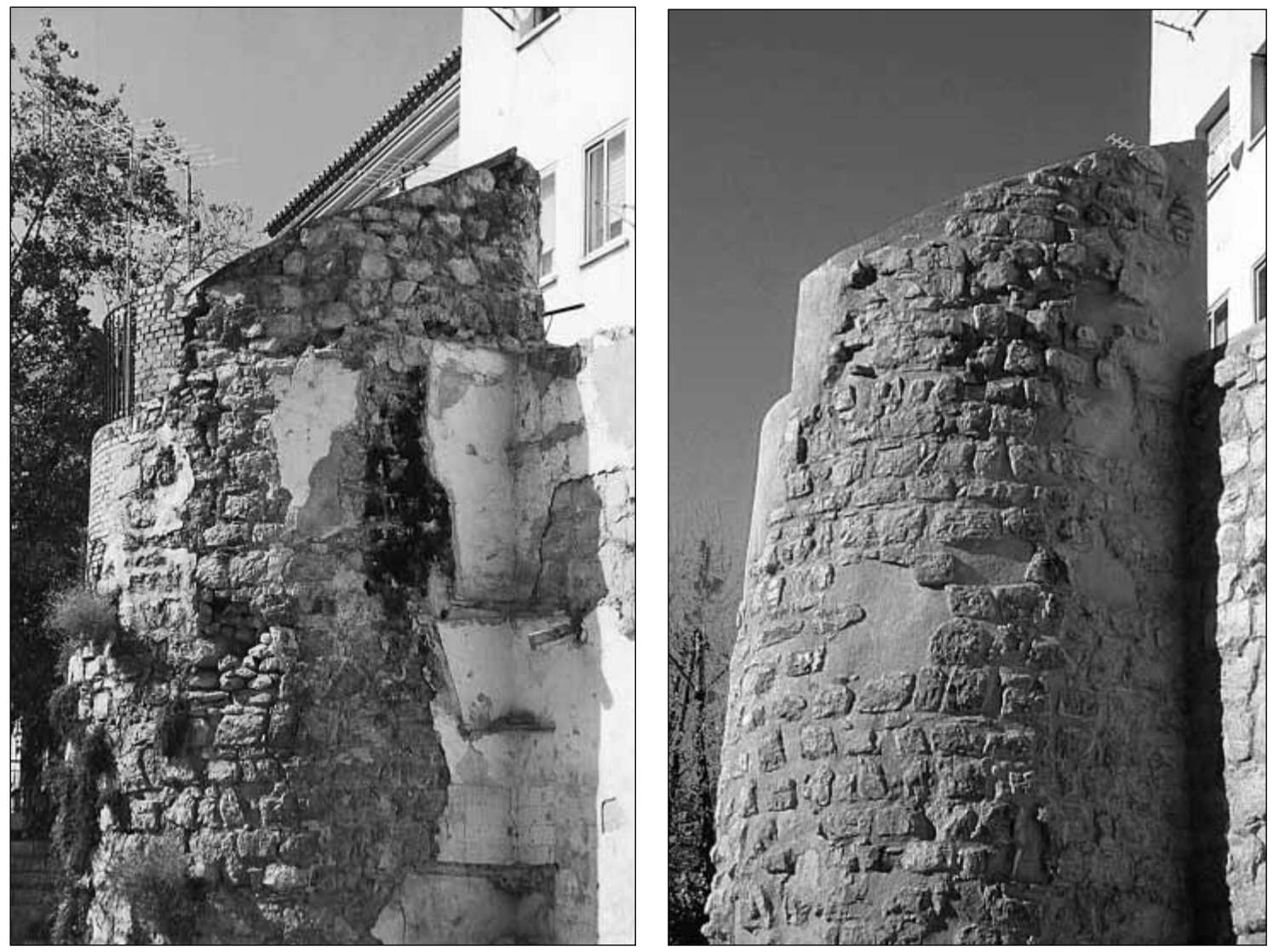

Láminas 10 y II. Estado del torreón antes y tras la intervención. 


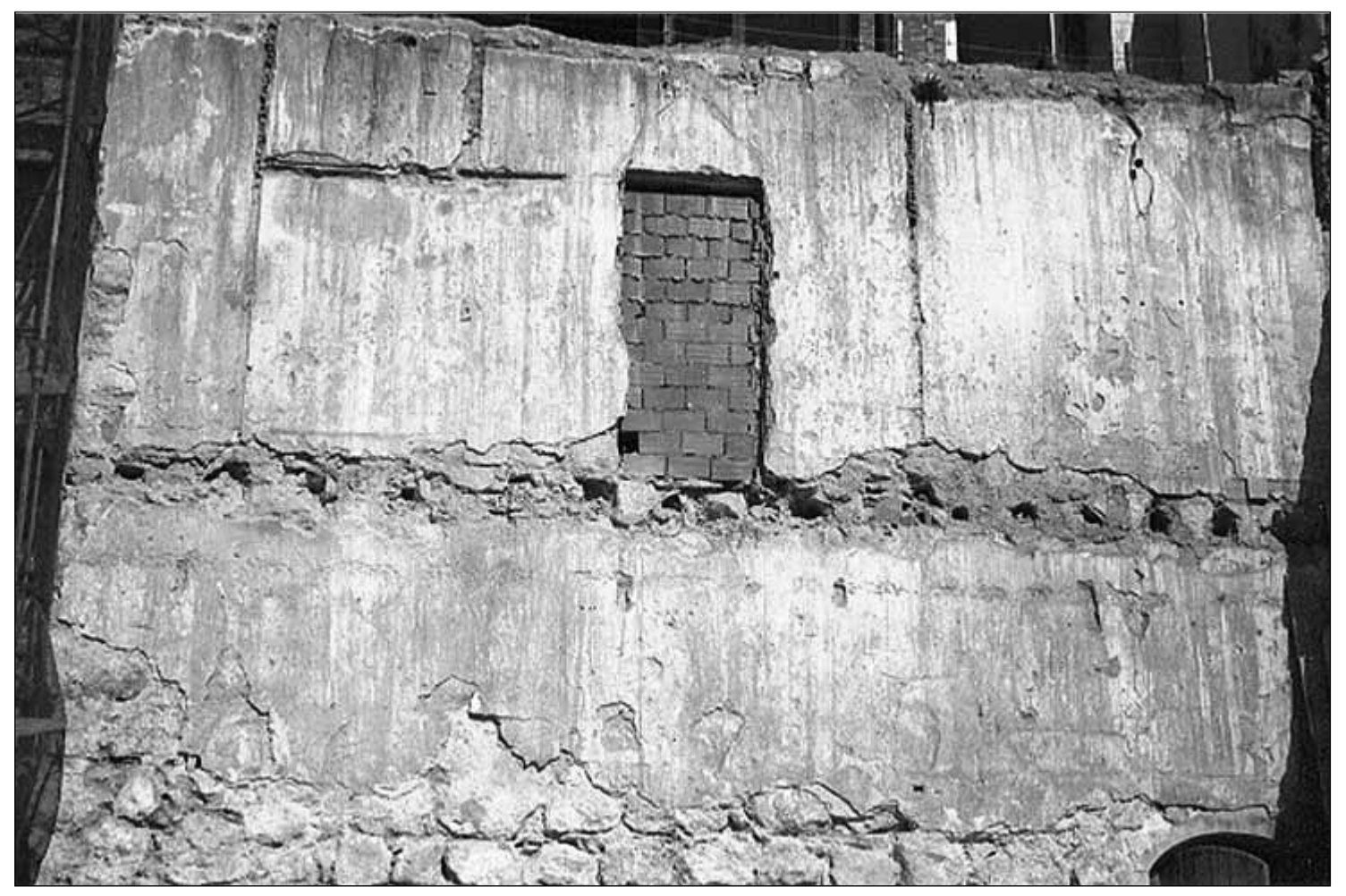

Lámina I2. Lienzo de muralla intervenido. Estado previo a la restauración.

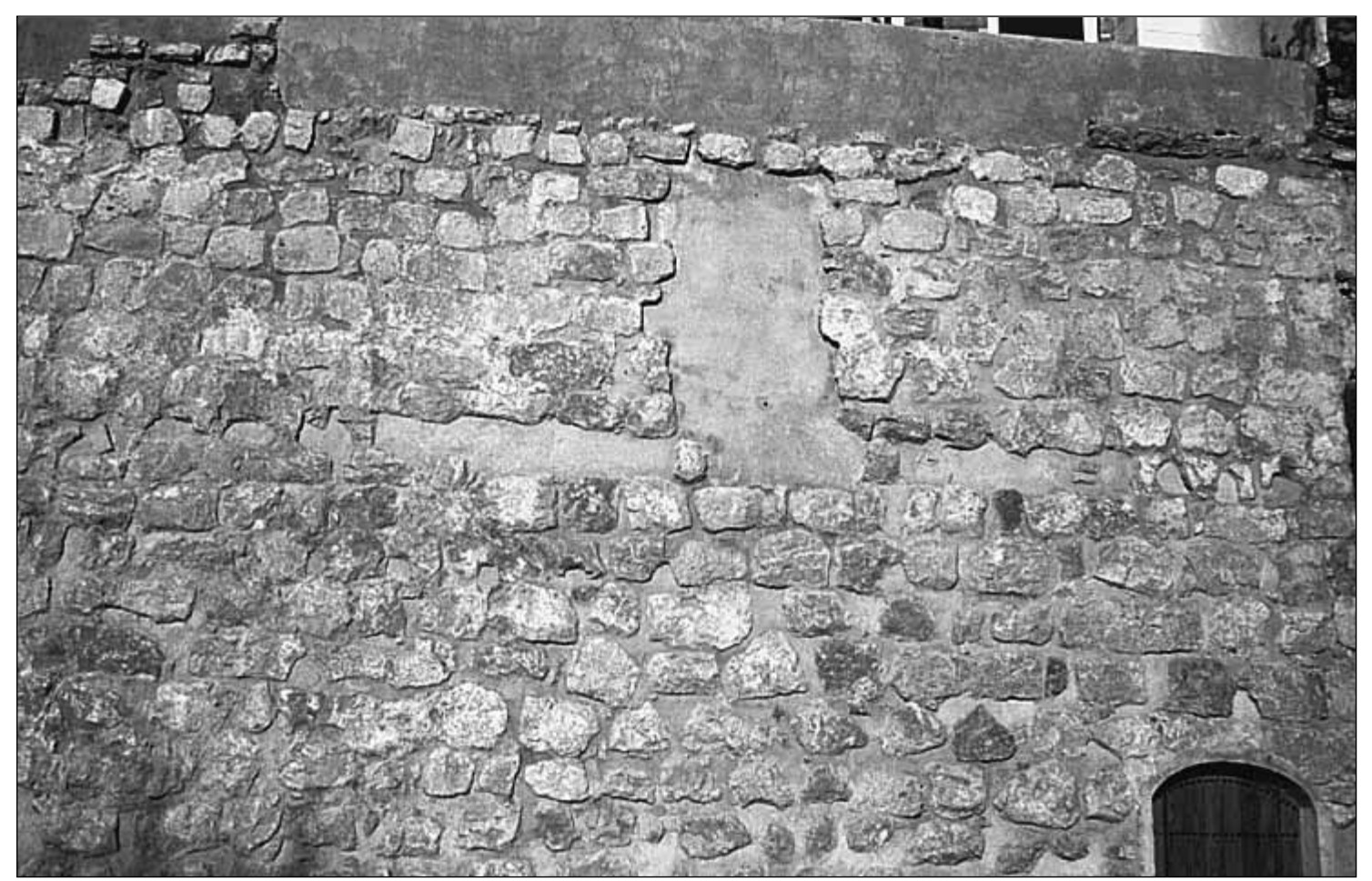

Lámina I3. Lienzo de muralla intervenido. 

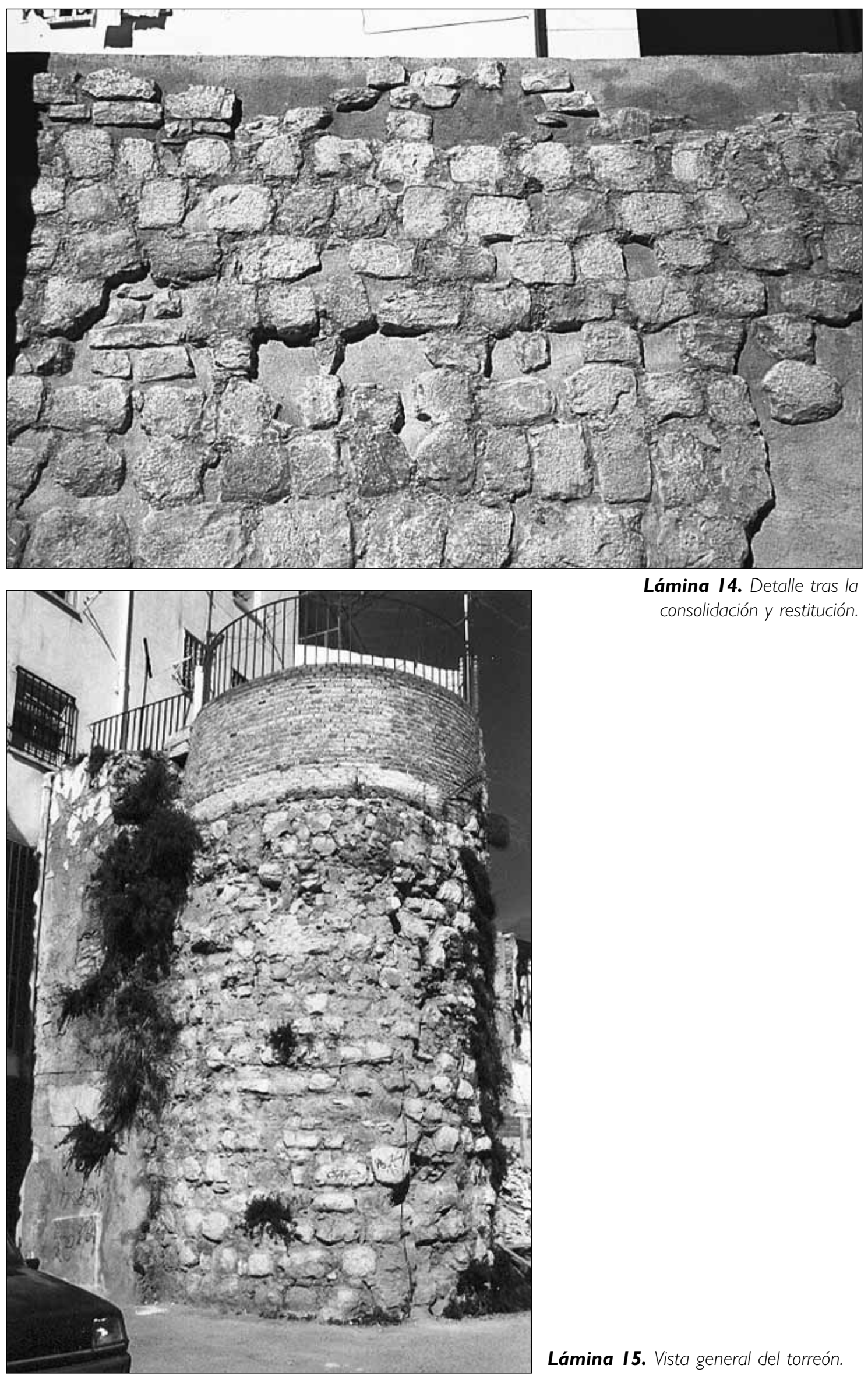

Lámina I4. Detalle tras la consolidación y restitución.

Lámina I5. Vista general del torreón. 


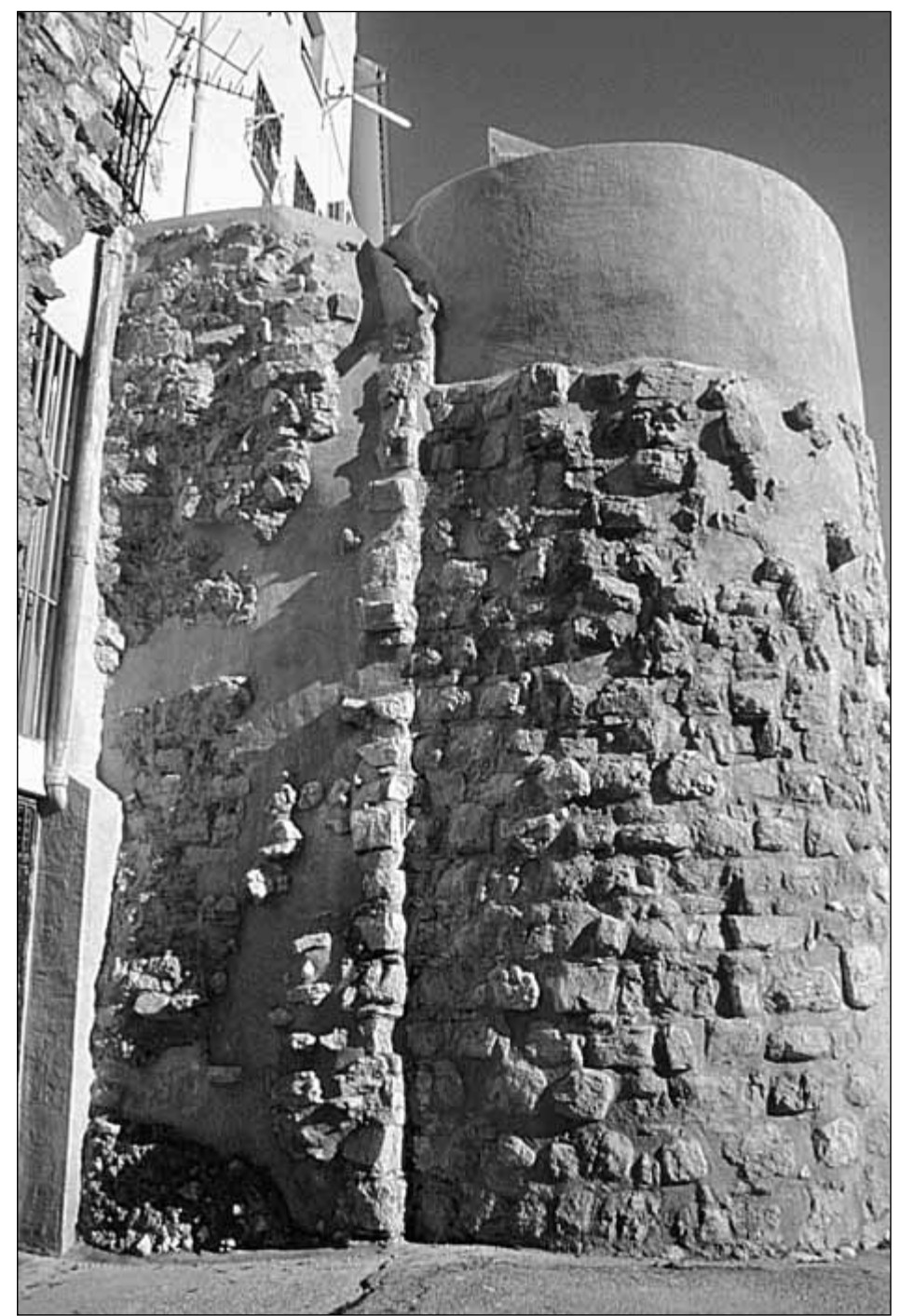

Lámina I6. Vista general del torreón tras la intervención.

Lámina I7. Aspecto del tramo de muralla finalizada la intervención.

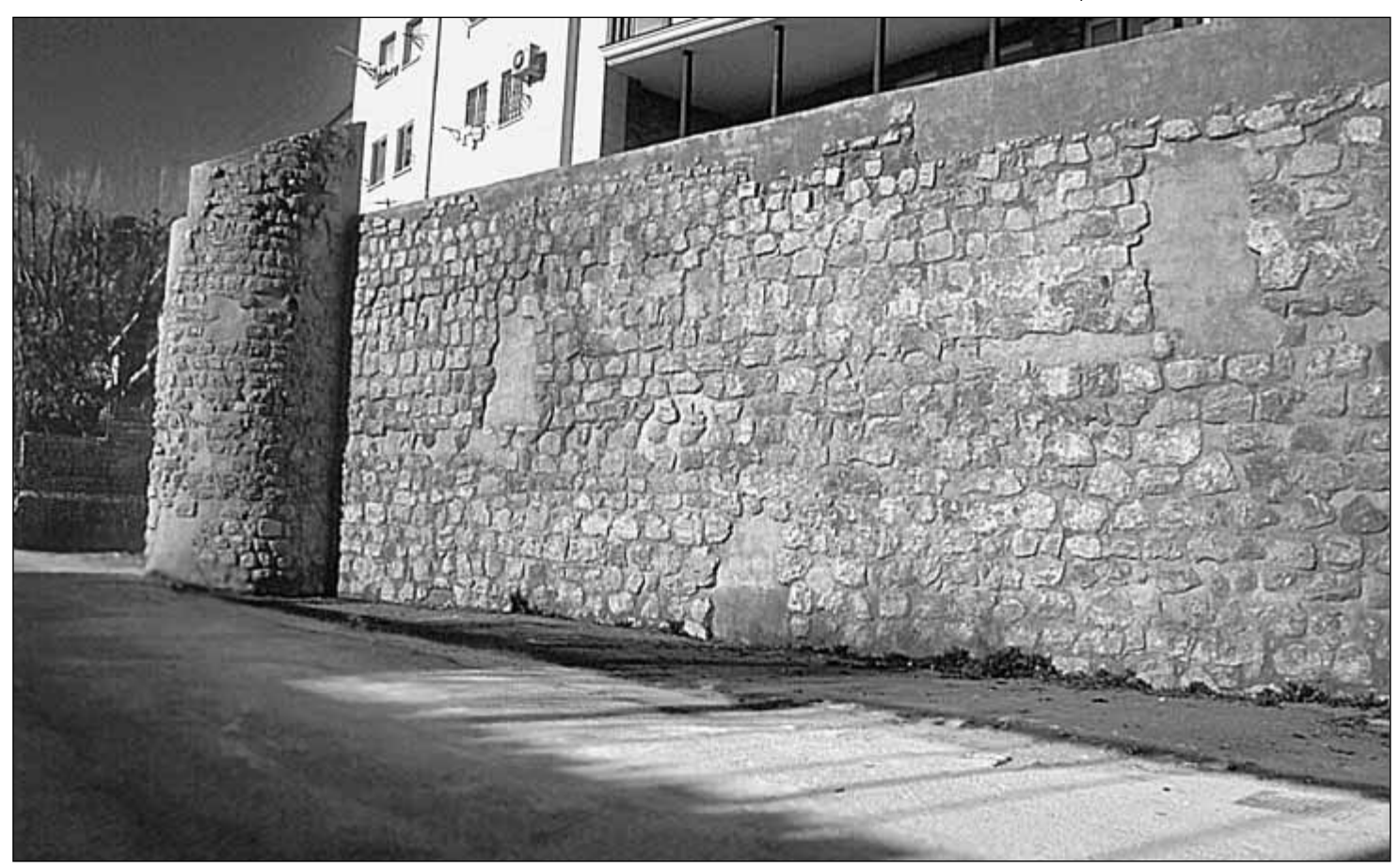




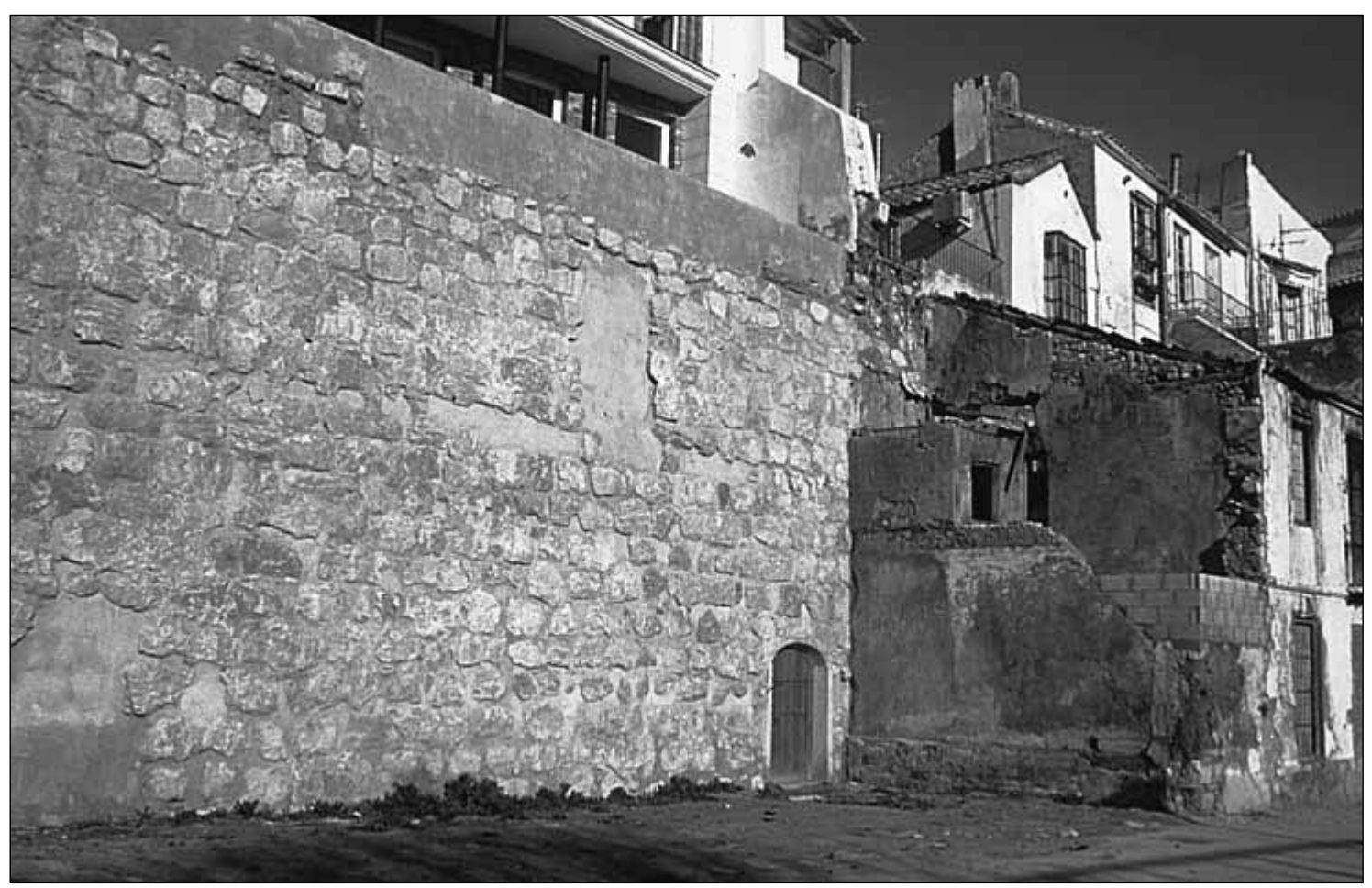

Lámina I8. Lienzo restaurado junto a edificaciones anexas. 